7

\title{
Song type variations of Louisiana Waterthrush (Parkesia motacilla) and their geographic distributions
}

W. Ross Silcock ${ }^{1}$, Shari L. Schwartz ${ }^{2}$, John U. Carlini ${ }^{2}$, and Stephen J. Dinsmore ${ }^{3, *}$

${ }^{1}$ Rosslyn L.L.C., Tabor, IA, United States of America.

${ }^{2}$ Wachiska Audubon Society, Lincoln, NE, United States of America.

${ }^{3}$ Department of Natural Resource Ecology and Management, Iowa State University, Ames, IA, United States of America.

* Corresponding author

E-mail: cootji@@iastate.edu (6) (1)

(1)

1
(1) 7 9 1

2

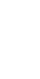




\section{About the authors}

W. Ross Silcock

ROLES: Conceptualization, Data curation, Investigation, Visualization, Writing - original draft, review \& editing AFFILIATION: Rosslyn L.L.C., Tabor, IA, United States of America.

\section{Shari L. Schwartz}

ROLES: Conceptualization, Data curation, Investigation, Visualization, Writing - original draft, review \& editing AFFILIATION: Wachiska Audubon Society, Lincoln, NE, United States of America.

\section{John U. Carlini}

ROLES: Data curation, Investigation, Writing - review \& editing AFFILIATION: Wachiska Audubon Society, Lincoln, NE, United States of America.

\section{Stephen J. Dinsmore}

ROLES: Data curation, Formal analysis, Funding acquisition, Visualization, Writing - original draft, review \& editing University, Ames, IA, United States of America.

The authors have declared that no competing interests exist.

\section{Competing interests}




\section{Abstract}

Louisiana Waterthrush (Parkesia motacilla) is a familiar singer in the Western

85 Hemisphere family Parulidae, yet apparent geographic variations in its song and potentially related causal mechanisms have not received detailed examination in previously published

87 studies. Here, we analyzed song pattern variations of 651 Louisiana Waterthrush singers in audio spectrogram recordings obtained from our field work and publicly accessible bioacoustics archives. Visual and auditory assessment of the introductory note sequence of each song identified three distinct song types (A, B, and C) and $88.3 \%$ of the songs were assigned to one of these types. Linear Discriminant Analysis and Random Forest methods were used to verify the assignments and showed strong agreement (>90\%) for Type A with slightly less agreement on Types B and C. User error rates (proportion of the Linear Discriminant Analysis classifications that were incorrect) were $<10 \%$ for Types A and B, but $26 \%$ for Type C, while producer error rates (proportion of the song type for which the Linear Discriminant Analysis was incorrect) were $>25 \%$ for Types A and C, but $<5 \%$ for Type B. Our findings confirmed in a subset of 87 individuals that most between-individual variation was in the number of notes and note sequence duration while most within-individual variation resulted from the percent of downstrokes. The

99 location of each singer was plotted on a map of the breeding range and results indicated the song types have large-scale discrete geographic distributions that co-occur in some regions but not range-wide. Evaluation of the distributions provided tentative support for a hypothesis that two of the song types may independently exhibit congruence with the geographic extent of Pleistocene glacial boundaries and the third song type may be distinguished by a lack of 104 congruence, but further investigation is needed to elucidate whether the song variations represent subpopulations with three separate evolutionary histories. 
Keywords: geographic song variations, Parkesia motacilla, Pleistocene glacial maxima

\section{Introduction}

Geographic variation in songbird vocalizations has been documented in nearly all

111 rigorously studied species [1,2] and can be the consequence of various factors [3].

112 Imitative learning promotes geographic variation when cultural transmission of songs

113 between generations allows shared novel vocalization patterns in song structure to arise

114 through inaccurate learning and appearance of new components [4-6]. Nevertheless,

115 variation in vocalizations is not unrestrained. Instead of copying the range of sounds to

116 which they might be exposed, juvenile oscines preferentially learn the vocalizations

117 characteristic of their species [7] or subspecies [8], and variations that arise during song

118 evolution may be constrained or redirected by genetically-based mechanisms such as

119 physiological song production abilities [3]. Variation may also be limited within small

120 colonizing or isolated populations that arise from genetically depauperate founder

121 populations such as those on islands or in recently deglaciated areas populated from glacial

122 refugia [9-12]. Populations that become geographically isolated undergo random cultural

123 drift [13], and the songs of isolates may ultimately evolve to the extent that conspecifics in

124 other populations alter their responses which can lead to reproductive isolation [14] and

125 divergence as was found with Australia's Chowchilla (Orthonyx spaldingii) whose song

126 structure has large-scale geographic variations in bandwidth and frequency peaks attributed

127 to cultural drift during isolation in Pleistocene refugia [15]. 
A combination of multiple evolutionary processes may influence geographic song variation as was observed in the bandwidth and internote duration variances between eastern and western

131 Common Yellowthroats (Geothlypis trichas) by Bolus [16], who noted sexual selection can be a

132 contributor that reinforces changes in song structure. Although nearly a third of all female

133 oscines are not known to sing [17], they must nonetheless learn their parental song type

134 alongside their male siblings in order to recognize and select a conspecific mate [18, 19]. Song

135 dialects, defined by Mundinger [20] as variation between song forms with loosely discrete

136 boundaries, can be distinguished by both males and females of White-crowned Sparrow

137 (Zonotrichia leucophrys) subspecies nuttalli [21]. Kroodsma [22] suggested certain populations

138 with songs that differ discontinuously may possess differing evolutionary histories as has been

139 demonstrated by the closely related and phenotypically similar taxonomic pairs of Marsh Wrens

140 (Cistothorus palustris plesius and C. p. iliacus) $[22,23]$ and Eastern and Western meadowlarks

141 (Sturnella magna and S. neglecta) [24, 25]. In regions of recontact, singing eastern and western

142 Marsh Wrens and Eastern and Western meadowlarks evoke territorial defense from both

143 respective male congeners despite their contrasting songs, yet females of both pairs of taxa

144 reserve receptivity responses solely for singers of their parental song type [22, 24]. The

145 importance of female discrimination was demonstrated in a study of sympatric Eastern and

146 Western meadowlarks [26] in which the absence of song convergence was attributed to selection

147 in order to oppose the establishment of a single song type and avoid interspecific matings in the 148 area of sympatry. 
Song divergence has been correlated with geographic variation in numerous avian subpopulations [16, 27-29]. It has been assumed that Louisiana Waterthrush exhibits no

152 phenotypic or genotypic geographic variation [30] in contrast with sister species Northern

153 Waterthrush (Parkesia noveboracensis) [31], although Mattsson et al. [30] proposed

154 subpopulations could potentially arise from discontinuous waterways on breeding grounds. A

155 lack of connectivity between some riparian corridors may limit dispersal as suggested by

156 Mattsson [32] for Louisiana Waterthrush, and by Machtans for other forest songbirds [33].

157 Geographic discontinuities in song structure can occur in species that have a pattern of limited 158 dispersal and learn relatively simple repertoires in the natal region during the pre-dispersal 159 period [3], the latter characteristic having been documented in Louisiana Waterthrush [30, 34, $16035]$.

163 in some Neotropical migrants as exemplified by the unnecessarily circuitous migratory pathway

170 succeeded by glacial intrusions that separated and shifted populations into discrete refugia for $171 \sim 100,000$-year periods [45]. East of the Rocky Mountains across what is presently Louisiana

172 Waterthrush's breeding range [46], nearly all of the Laurentide Ice Sheet reached maximum 
173 extent during the earlier pre-Illinoian Stage glaciations, whereas only the central and eastern

174 portions of the ice sheet reached commensurately extensive glacial maxima during the later

175 Illinoian Stage, and only the eastern portion of the ice sheet reached a comparable extent during

176 the Last Glacial Maximum (LGM) of the most recent Wisconsinan Stage [42, 47]. During major

177 glaciations, high-altitude periglacial permafrost in the Appalachian Mountains [48, 49] would

178 have adversely affected habitability adjacent to the ice sheet. Periglacial permafrost conditions at

179 lower elevations directly west of the Appalachians were restricted to a narrow band which

180 allowed temperate forest vegetation to exist close to the ice margin, but farther west, permafrost

181 conditions along the western edge of the ice sheet covered a wider expanse during the LGM [43,

$18250,51]$. Glacial vicariance impacted many aquatic and terrestrial taxa in the southeastern United

183 States [52 - 55] during periods of glacial maxima as the ice sheet at maximum extent adjoined

184 the Mississippi Embayment alluvial landscape [56, 57] and divided southeastern refugia into

185 eastern and western locations referred to as Appalachian and Ozark centers of endemism by

186 Strange and Burr [58]. The isolating combination of ice sheet and Embayment's habitat

187 barrier produced divergent lineages of North American salamanders [59, 60] and stream

188 dwelling "highland fishes" [58, 61], all of which share aquatic invertebrate prey sources with

189 Louisiana Waterthrush and may themselves be included in its diet [30]. The Embayment's

190 bisection of the distributions of some Parulidae species is evident in the current

191 breeding ranges of Louisiana Waterthrush, Prairie Warbler (Setophaga discolor), and Worm-

192 eating Warbler (Helmitheros vermivorum) [46].

As a result of observing Louisiana Waterthrush song pattern variations locally, we accessed 
196 the species' entire breeding range. In this study, we analyzed the song types identified in the

197 recordings, plotted their geographic distributions, assessed conceivable explanations for the

198 configuration of the distributions, and evaluated each song type's distribution for potential

199 correlation with Pleistocene glacial conditions.

200

201 Materials and methods

203 Louisiana Waterthrush ecology

The Louisiana Waterthrush is unique among Parulidae as the only bird in the southeastern

United States that breeds exclusively along forested streams [32]; prime habitat consists of

213 on the breeding grounds but after females arrive and are paired with males, singing sharply

214 declines [34, 63]. Eaton [34] reported rarely hearing the "advertising song" from the time of pair

215 formation until incubation started around 3-4 weeks later [30], with reinstated song never

216 delivered as often as prenuptial singing. Males sing infrequently during the incubation and early

217 nestling phases, and nestlings may on occasion also be exposed to female song [30]. Several 
218 females have been observed singing a version of male song that is recognizable but has a less

219 complicated and softer delivery and apparently functions to summon the male during incubation

220 recess [30]. Males at the latitude of Ithaca, New York sang occasionally in late June and early

221 July while tending semi-independent juveniles, and had a resurgence of song in the first half of

222 August after their molt was complete just prior to their early departure for wintering grounds

223 [34]. The dependency period for fledglings lasts 3-4 weeks [30] after which some but not all may

224 begin to wander from the natal area to varying degrees. Two juveniles banded by Eaton [34],

225 were documented $2.0 \mathrm{~km}$ and $4.8 \mathrm{~km}$ from their natal areas just over a month after leaving the

226 nest.

The repertoire of Louisiana Waterthrush is limited to a single song which is deemed to be its

230 primary song when delivered without the extended conclusion that is appended occasionally

231 [30]. Each male's song is unique and individually recognizable [63, 64]. Variation in the pattern

232 of introductory notes sung by some individuals has been noted [35]. Typical primary songs

233 commence with a repetitive series of introductory notes and culminate in a phrase of non-

234 repetitive notes [35]. The extended song conclusion can be appended to the primary song [65]

235 singly or in repetition and is usually included when the singer is in territorial defense mode [35].

236 It is thought that when this extended song is added to the primary song, Louisiana Waterthrush's

237 song performs the same functions that some Parulidae species achieve by using a repertoire of

238 more than one song $[65,66]$. Unpaired Louisiana Waterthrush males often conclude the primary 
239 song without the extended song [64] while paired males appear to be more apt to add the

240 extended conclusion $[30,65]$.

\section{Song type characterization}

To investigate the range-wide distributions of the song type variations we had encountered in field work, all Louisiana Waterthrush audio recordings at Macaulay Library [67] and xenocanto [68] from 1957 through 2018 were inventoried, and 820 spectrograms containing 4000+

246 songs were obtained. Visual and auditory examination of note shapes and sequences

247 in the spectrograms allowed for identification of recordings shared by counter singing

248 individuals whose songs required separate evaluation, and multiple recordings of a single singer 249 submitted from the same location. After the elimination of recordings that were redundant, those 250 that lacked sufficient quality for measurement, and a few from wintering grounds south of the

251 United States, the resulting database (S1 Appendix) contained 3833 songs of 651 individual

252 singers. For spectrograms containing more than one song, the RANDBETWEEN function in

253 Microsoft Excel was used to select one song per singer at random. Only the series of

254 introductory notes ("note" defined as a continuous trace on a spectrogram) that initiates the

255 primary song was evaluated; we refer to this series as the Introductory Note Sequence (INS) (Fig

256 1). Raven Lite 2.0 sound analysis software (Cornell Laboratory of Ornithology) was utilized to

257 measure the INS in each of the 651 songs for the seven following variables: number of notes

258 ("Notes"), note sequence duration (“Duration"), duration per note ("Dur_note"), percent of

259 duration spent singing the downstroke portions of notes (Percent_down”), minimum frequency

260 (Min_freq"), maximum frequency ("Max_freq"), and frequency span (“Freq_span”). The phrase 
261 of notes that follows the INS and terminates the primary song is referred to as the Secondary

262 Note Sequence (SNS); this phrase was distinguished from the INS by its miscellany of notes that

263 extend to lower minimum frequencies than the minimum frequencies of the more uniformly

264 patterned INS notes. SNS patterns shared regionally by multiple singers provided an additional

265 aid for distinguishing the SNS from the INS, but because these apparent SNS geographic

266 distributions plotted independently of INS distributions, that part of the primary song was not

267 analyzed. The extended song conclusion that is appended inconsistently to the primary song was

268 also excluded from analysis. Some singers uttered either a single call note or a brief "grace note"

269 preceding the INS delivery but many singers did not employ these notes that often were too

270 abbreviated to yield tonality. Some individuals sang INS notes with faint polyphonic signatures

271 stacked vertically above the notes in the spectrogram image but these marks were presumed to

272 indicate overtone frequencies so were not evaluated. After careful visual and auditory

273 examination, the note shapes in the INS of each song were assigned to one of the three song

274 types, or in cases where assignment was unclear, categorized as Unassigned.

276 Fig 1. Spectrogram examples of the A, B, and C note types. Two examples (from S1

277 Appendix) are shown of each note type. Type $\mathrm{A}$ is comprised of alternating upstroke and

278 downstroke note pairs, Type B employs downstrokes only, and Type C notes undulate both

279 upwards and downwards. 
Our goal was to identify and describe key characteristics of Louisiana Waterthrush songs, confirm the accuracy of our subjective classification of three song types, and understand which (if any) of seven song features were good predictors of song type. We used descriptive statistics

285 (mean + SD) to characterize seven quantitative measures of song type. We then used Linear Discriminant Analysis (LDA) [69] to classify song type on the basis of the seven measures. For

287 this analysis, we eliminated frequency span because it was strongly correlated with measures of minimum and maximum frequency, was highly variable, and was generally uninformative with respect to song type. Because the six remaining variables had different scales, we standardized them $(\mathrm{SD}=1$ for all of them) and then plotted them for visual inspection. This plot helped us interpret the influence of each of the six predictors of song type on a two-dimensional plot of

292 song types for this analysis. For example, observations with a high value of Notes (above the 293 mean) and a low value of Duration (below the mean) will be plotted in the bottom left of the

294 LDA scores plot (e.g., in the direction of Notes and opposite the direction of Duration).

295 Similarly, variables like Max_freq and Min_freq that are close to the origin $(0,0)$, even after

296 rescaling, have little impact on the position of the observations in the LDA scores plot. This was

297 also confirmed with the use of a Random Forest (RF) analysis [70], which is similar to the LDA

298 but allows interactions between measures. Lastly, we used multiple song measures to

299 describe the intra- and inter-song variation in a sample of Louisiana Waterthrush spectrograms.

300 We fit a variance-covariance model to the data where individual was a random variable and there

301 were replicates within each individual. We used the Intra-Class Correlation (ICC), which is the 302 group variance divided by total variance, to assess the proportion of variation that was due to 303 within- and between-individual variation. 


\section{Map of assigned singer locations with glacial environment}

306

Recording locations were represented on a map of the eastern United States on Google My Maps and National Institute of Statistics and Geography map data

\section{(https://www.google.com/maps/d/u/0/viewer?mid=1PAkxNYqk 7iRslxEd57mgqR38u0\&1l=40.}

$\underline{669561163969384 \% 2 \mathrm{C}-83.80830025 \& \mathrm{z}=5)}$ ) with color-coded pin markers placed at described

locales or latitude and longitude coordinates provided by recordists. The 11 singers recorded in

Florida are presumed migrants but were retained to contribute additional songs for analysis.

Pleistocene glacial maximum boundaries were indicated on the map with gray screens that depicted the pre-Illinoian and Illinoian major glacial stages and the Wisconsinan LGM stage was represented with a thick black outline; map sources [42, 47, 71-75] encompassed both general and detailed illustrations to most accurately delineate former glacial boundaries for comparison to contemporary Louisiana Waterthrush locations. The high-altitude periglacial permafrost region in the Appalachian Mountains adjacent to the glacial boundary [48] was also depicted with a gray screen, the Wisconsinan LGM periglacial extent was depicted with a white line [50, 51], and the Mississippi Embayment region [74] that bisected suitable habitat in tandem with the ice sheet was portrayed with a thin black outline.

\section{Results}

We measured 3833 Louisiana Waterthrush songs representing 651 individual singers (S1 Appendix) in this study. Visual/auditory assignments placed $88.33 \%$ of the songs into one of three song type groups designated as Type A $(72 ; 11.06 \%)$, Type B $(404 ; 62.06 \%)$, or Type C 
(99; $15.21 \%)$. The remaining $11.67 \%$ were categorized as Unassigned ("Un": Table 1) and were omitted from the analyses depicted below in Figs 2, 4, and 5 and Tables 2 and 3.

\section{Song type classification}

For this analysis we used a subset of 651 songs, one per individual, for which we measured seven attributes (Table 1). The LDA coefficients varied across the six included variables (Fig 2) and helped interpret a plot of song type on the two LDA axes (Fig 3). Type A songs have above average values for Notes and below average values for Duration; the other four variables had little role in pulling Type A songs away from the other song types (Fig 3). The confusion matrix for three song types (Table 2) showed that the model performed well with most misclassifications occurring between Types B and C. The user error rates (proportion of the LDA classifications that were incorrect) were $<10 \%$ for Types A and B, but $26 \%$ for Type $\mathrm{C}$. The producer error rates (proportion of the song type for which the LDA was incorrect) were $>25 \%$ for Types $\mathrm{A}$ and $\mathrm{C}$, but were $<5 \%$ for Type $\mathrm{B}$. The LDA equations were:

LDA1 $=-1.369 *$ Notes $+4.212 *$ Duration $-11.69 *$ Dur_note $+0.07852 *$ Pct_down + $0.001499 *$ Min_freq $+0.0006093 *$ Max_freq -10.379

LDA2 $=-1.710 *$ Notes $+2.690 *$ Duration $+3.290 *$ Dur_note $-0.06055 *$ Pct_down + $0.0003522 *$ Min_freq $+0.00006326 *$ Max_freq +2.937 .

\section{Fig 2. Plot showing the scaling coefficients of the Linear Discriminant Analysis of Louisiana}

Waterthrush song types. The six predictors of song type are arranged around the overall scaled 
347 mean $(0,0)$ to indicate their relative influences. The six variables plotted are the number of notes

348 (Notes), note sequence duration (Duration), the duration per note (Dur_note), the percent of

349 duration spent singing the downstroke portions of notes (Pct_down), the minimum frequency

350 (Min_freq), and the maximum frequency (Max_freq).

1957-2018.

Table 1. Summary statistics for measures of Louisiana Waterthrush song types.

\begin{tabular}{lrrrrrrrr} 
Type & $\mathrm{n}$ & Notes & Duration & Dur_note & Pct_down & Min_freq & Max_freq & Freq_span \\
\hline A & 72 & 4.40 & 1.03 & 0.24 & $30(9)$ & 4019 & 6056 & 2037 \\
& & $(1.27)$ & $(0.25)$ & $(0.05)$ & & $(273)$ & $(481)$ & $(478)$ \\
B & 404 & 2.81 & 0.77 & 0.27 & $53(9)$ & 4442 & 6853 & 2411 \\
& & $(0.58)$ & $(0.20)$ & $(0.04)$ & & $(230)$ & $(455)$ & $(441)$ \\
$\mathrm{C}$ & 99 & 2.86 & 0.84 & 0.30 & $33(9)$ & 4248 & 6373 & 2124 \\
& & $(0.61)$ & $(0.20)$ & $(0.05)$ & & $(259)$ & $(451)$ & $(465)$ \\
Un & 76 & 3.67 & 0.94 & 0.27 & $37(11)$ & 4187 & 6443 & 2256 \\
& & $(1.28)$ & $(0.25)$ & $(0.05)$ & & $(423)$ & $(583)$ & $(571)$ \\
\hline
\end{tabular}

356 Numbers are means (SD) and are given for the seven quantitative measures of each song.

359 Discriminant Analysis of seven song attributes.

Type A Type B Type C Producer error

$\begin{array}{ccccc}\text { Type A } & 54 & 7 & 11 & 25.0 \% \\ \text { Type B } & 4 & 386 & 14 & 4.5 \%\end{array}$



Type C
27
71
$28.3 \%$

User error $\quad 8.5 \% \quad 8.1 \% \quad 26.0 \%$

The user error is calculated by column and is 1 - (\# correct/total). The producer error is the same but is calculated for rows.

364 similar results (Table 3). Finally, we plotted misclassifications between the assigned song type

365 and both the LDA classification (Fig 4) and the Discriminant Function (DF) classification (Fig 5) to better indicate where these methods showed disagreement.

\section{Louisiana Waterthrush song types.}

$\begin{array}{lll}\text { Style Type A } & \text { Type B }\end{array}$

370 Rows are the Linear Discriminant Analysis assignments and columns are the Random Forest

371 assignments. 
373 Fig 4. Errors between visual/auditory song type assignments and song type assigned by the

374 Linear Discriminant Analysis. "No error" indicates song types with a match between assigned

375 song type and Linear Discriminant Analysis assignment. “AB error” indicates song types for

376 which the assigned type and Linear Discriminant Analysis type included one Type A and one

377 Type B. "AC error" and "BC error" map errors between those respective pairs of song types.

Fig 5. Errors between visual/auditory song type assignments and song type assigned by the

Discriminant Function. "No error" indicates song types with a match between assigned song

type and Discriminant Function assignment. "AB error" indicates song types for which the

assigned type and Discriminant Function type included one Type A and one Type B. "AC error" and "BC error" map errors between those respective pairs of song types.

\section{Within- and between-song variation}

To assess the contribution of within- and between-song variation, we used a dataset 
Table 4. Variance components and Intra-Class Correlation (ICC) for within- and betweensong variation in Louisiana Waterthrushes.

\begin{tabular}{llll} 
Song attribute & Between individuals & Within individual & ICC \\
\hline Notes & 1.030000 & 0.078400 & 0.929 \\
Duration & 0.041700 & 0.008920 & 0.824 \\
Dur_note & 0.001810 & 0.000300 & 0.858 \\
Pct_down & 0.017800 & 0.139000 & 0.928 \\
Min_freq & 0.000014 & 0.009840 & 0.934 \\
Max_freq & 0.000031 & 0.000151 & 0.954 \\
Freq_span & 0.000022 & 0.000219 & 0.909 \\
\hline
\end{tabular}
comprised $11.67 \%$ (76) of the total and were designated as Unassigned. The INS of the Unassigned songs sorted into three subcategories: "mixed types", with notes incorporated from two or in one example three types $(38 ; 5.83 \%)$, "equivocal", which were open to more than one interpretation $(30 ; 4.61 \%)$, and "anomalous", involving note shapes or patterns atypical of Louisiana Waterthrush $(8 ; 1.23 \%)$ (Fig 6). The geographic distribution of "mixed types" songs was range-wide, although when displayed on the map concurrently with the A, B, and C types, 30 out of 38 "mixed types" singers occurred in areas where two or three types were present

405 whose INS notes corresponded to notes employed by "mixed types" singers in the vicinity

$407 \quad 669561163969384 \% 2 C-83.80830025 \& z=5)$. Singers of the undetermined "equivocal" songs had 408 a distribution that conformed with the distributions of Types $\mathrm{A}$ and $\mathrm{C}$ and were absent in most of 409 the LGM deglaciated zone where Type B predominated. At least half of the "equivocal" songs 410 had INS patterns that included what appeared to be variations on one or more Type A note pairs 411 but these note pairs lacked the symmetry of alternating upstrokes and downstrokes typically seen 
412 in the Type A note pair pattern and so were left as Unassigned. The eight "anomalous" singers

413 mostly occurred in the eastern part of the range and consisted of five singers with INS patterns

414 that were a rapid series of abbreviated upstrokes, and three singers that lacked variation between

415 the minimum frequencies of the INS and SNS notes in possible examples of SNS notes

416 substituted for the INS series.

Fig 6. Spectrogram examples of Unassigned songs. Two examples (from S1 Appendix) were selected to represent each of the three subcategories.

\section{Song type distributions and comparisons with glacial environment}

Markers plotted on the map to denote the song locales showed Types A, B, and C had discrete geographic distributions that overlapped in some but not all areas (Fig 7). A depiction of

Pleistocene glacial maxima overlaid on the map indicated all three types were distributed widely

425 across previously unglaciated areas of the current breeding range with the exception of the

426 Mississippi Embayment where occurrence was limited to Crowley's Ridge (Fig 7). The majority

427 of Type B singers $(219 ; 54.2 \%)$ were located in the deglaciated zone of the LGM where that type

428 was exclusively ubiquitous. Conversely, occurrences in the LGM deglaciated zone were rare for

429 Type A $(2 ; 2.8 \%)$ and minimal for Type C $(20 ; 20.2 \%)$ with most of those occurrences recorded

430 near the East Coast (Table 5, Fig 7). Type A singers had notable populations in the Maryland

431 region and Southern Appalachians and were almost entirely absent between the Appalachians

432 and the Embayment but predominated west of the Embayment in the region that remained ice-

433 free during the LGM. Type A was the only song type found along the southwestern edge of the 
434 breeding range with the exception of two Type B singers at the range's southwest terminus. Type

435 C singers occurred primarily east of the Embayment with some located in the LGM deglaciated

436 zone, but the majority were on the unglaciated side of or abutting the Illinoian glacial maximum

437 boundary, and this song type was the only type that occurred directly northeast of the

438 Embayment. A few Type C singers were also observed west of the Embayment where their

439 limited distribution more closely paralleled the distribution of Type A than Type B.

Fig 7. Mapped song type locations with glacial environment. Distributions of the four

442 designated categories relative to pre-Illinoian and Illinoian glacial maxima and high-altitude

443 periglacial permafrost represented by gray screens, and to Last Glacial Maximum boundary

444 indicated by a thick black line, with thin black outline representation of the Mississippi

445 Embayment.

447 Table 5. Percentage of each song type distributed north and south of the Last Glacial

448 Maximum boundary.

\begin{tabular}{|cc|c|c|c|c|}
\hline \multicolumn{2}{|c|}{ Song Type } & North & $\%$ & South & $\%$ \\
\hline A & $(\mathrm{N}=72)$ & 2 & 2.8 & 70 & 97.2 \\
\hline B & $(\mathrm{N}=404)$ & 219 & 54.2 & 185 & 45.8 \\
\hline C & $(\mathrm{N}=99)$ & 20 & 20.2 & 79 & 79.8 \\
\hline
\end{tabular}




\section{Discussion}

The INS portion of most Louisiana Waterthrush songs consisted of a repetitive series of one of three note shape types that were assigned as Type A, B, or C. Statistical analyses supported assignments obtained from visual and auditory assessment and identified strong predictors of each type. Within the broader structure of each type's note shapes, there was considerable variance between individual singers in note sizes and dimensions. This individuality within the species' songs allowed for a multitude of singers to be identified and catalogued from the burgeoning supply of publicly available audio spectrograms, thus offering a largely untapped opportunity to study lineages and dispersal tendencies through unique song variations that are presumably culturally transmitted between generations.

Some insight into the assembly of Louisiana Waterthrush song was provided by examining the INS of "mixed types" singers in the Unassigned category. Twice as many "mixed types" singers sang a combination of notes from Types B and C as singers who combined Types A and B or Types A and C, the reason for which is unknown, but one factor may be Type A's near absence in the deglaciated zone where Types B and C co-occur (Fig 7;

https://www.google.com/maps/d/u/0/viewer?mid=1PAkxNYqk 7iRslxEd57mgqR38u0\&ll=40.6 69561163969384\%2C-83.80830025\&z=5). Each "mixed types" singer delivered an individually unique combination and pattern of INS notes with a level of consistency between repetitions on par with singers of Types A, B, and C songs. It is informative that most were recorded in the vicinity of two or three neighboring song types whose INS notes corresponded to INS notes in the "mixed types" songs nearby. The parsimonious explanation for these songs with a mixture of types in the INS is a scenario in which juveniles were exposed to adult males singing different 
474 song types on adjacent territories during a crucial learning period. In personal observations (S1

475 Appendix), adjacent territories were most frequently defended by males that shared the same INS

476 type, but it was not uncommon for males of differing INS types to also vigorously defend

477 adjacent territories. The low percentage (5.83\%) of total songs analyzed that have a mixture of

478 types in the INS is perhaps unexpected given the prevalent sympatry of the three discrete song

479 types. Careful inspection of the audio spectrograms indicated several instances of counter

480 singing males with differing song types but the presence of more than one type on a stream

481 typically did not result in any known neighboring "mixed types" singers. This observation leads

482 to questions relating to song convergence: why is there a paucity of songs with INS patterns

483 comprised of more than a single type, and why hasn't exposure to the different types sung by

484 neighbors over the course of time resulted in more Louisiana Waterthrush singers having

485 incorporated various combinations of INS note types as the "mixed types" singers have done? A

486 possible explanation for range-wide maintenance of distinct INS patterns consisting of a single

487 type might be female preference for uniform rather than "mixed types" INS patterns. This

488 plausibly could be similar to dialect recognition in female White-throated Sparrows or what is

489 seen between the taxonomic pairs of eastern and western Marsh Wrens and Eastern and Western

490 meadowlarks when the sympatric occurrence of those phenotypically similar congeners results in

491 females reserving receptivity for singers of their parental song type while singing males evoke

492 territorial defense from both taxa despite their contrasting songs that perhaps could be analogous

493 to contrasting INS patterns in Louisiana Waterthrush. Regarding female Louisiana Waterthrush

494 INS discrimination, we note here an observation of a "mixed types" singer that was defending a

495 territory on which juveniles were present, indicative of a "mixed types" singer having

496 successfully attracted a female who may or may not have shared the same "mixed types" 
497 lineage. Limited habitat at that locale accommodated only one male rival who sang a

498 corresponding "mixed types" song; this finding of adjacent singers that shared a unique "mixed

499 types" song pattern suggests a male had returned to his natal stream to vie for territory with a

500 related male. While some shared song patterns (INS + SNS) within the song types were found to

501 occur a considerable distance apart, with the greatest distance noted in a shared Type B

502 pattern found in the deglaciated zone $906 \mathrm{~km}(563 \mathrm{mi})$ apart, shared song patterns of all the types

503 were also commonly found on adjacent territories or streams, suggesting that as with the

504 matching "mixed types" neighbors, dispersal may be limited at times, a trait known to contribute

505 to geographic discontinuities in song structure.

508 separable variations in INS type raise other intriguing questions such as what factors could have contributed to the distributional differences between them? Latitudinal differences place Type B's distribution northernmost, Type A's distribution extending northwards the least, and Type area most recently covered by glacial ice and also appears to have the greatest presence in the

517 formerly uninhabitable region of high-altitude periglacial permafrost in the Appalachian

518 Mountains. It was pointed out by Li et al. [77] that postglacial migration of species almost 519 certainly involved more than simple range expansion from south to north, with one scenario 
520 having involved expansion from northerly glacial refugia; the current distribution of Type B

521 singers may be illustrative of such alternative expansions considering that type's current

522 predominance on what would have been newly available habitat following the recession of the

523 LGM. Type A may have undergone a similar expansion during an earlier interglacial period in

524 the same region as Type B's current distribution to the north of Type C's geographic stronghold,

525 and this proposition could provide an explanation for a puzzling gap in Type A's distribution

526 between the Appalachians and the region west of the Mississippi Embayment (Fig 7). Type A's

527 preponderance on the west edge of the breeding range could plausibly be explained if a

528 succeeding glaciation consistent with the Illinoian glacial maximum had then isolated a

529 subpopulation during convergence of the ice sheet with the Embayment, and facilitated an

530 expansion of Type A in the western region at a time when forest habitat would have prevailed in

531 parts of the Great Plains. West of the Embayment's bisection of the distributions, the

532 comparatively small Type A subset is disproportionately represented on previously unglaciated

533 terrain and in the area that has not been glaciated since pre-Illinoian episodes, yet it is nearly

534 absent from the neighboring LGM deglaciated zone populated by Type B (Fig 7). The literature

535 has no indication of heterogeneity in the specialized riparian breeding habitat utilized by

536 Louisiana Waterthrushes and so it is unlikely the discernible demarcation between Type

537 A's occurrence in areas that have not been glaciated since pre-Illinoian episodes and Type B's

538 major presence in the adjacent LGM deglaciated region can be attributed to differences in the

539 present-day habitat of those contiguous parts of the range. Alternatively, a heritable adaptation to

540 past glacial conditions akin to what is seen in Swainson's Thrush could feasibly account for the

541 difference in the distributions if such an adaptation is exhibited by Type A but not shared by

542 Type B. This rationale for Type A's distributional congruency with LGM glacial conditions west 
543 of the Embayment could also explain its occurrence entirely on previously unglaciated terrain

544 between the east side of the Embayment and the Appalachians, and similarly offer an

545 explanation for the abundance (35) of Type $\mathrm{C}$ singers in that same region which occur on the

546 previously unglaciated side of and abut the Illinoian glacial maximum boundary line, with only a

547 few (5) observed in the deglaciated zone across that same longitudinal span (Fig 7). Although

548 Type C's distribution largely parallels the distribution of Type A in that large majorities of each

549 occur in the unglaciated region or the region that has not been glaciated since the earlier pre-

550 Illinoian episodes, Type $\mathrm{C}$ is not as consistent as Type $\mathrm{A}$ in its distributional mirroring of glacial

551 maxima, and a portion (20.2\%) of Type C singers also occurs alongside Type B singers in the

552 LGM deglaciated zone. Half of Type C's occurrences in the LGM deglaciated zone were

553 recorded within $136 \mathrm{~km}(85 \mathrm{mi})$ of the East Coast but the reason for that greater density within

554 close proximity to the coast, with the remainder of occurrences more sparsely distributed across

555 the deglaciated zone, is not understood. Type B's overlapping distribution in the deglaciated zone

556 shows a comparable increase in density near the coast.

Geographic distribution is not the only attribute in which Type C displays overlap with Types

559 A and B. Of the three song types, Type A's INS frequencies extend the lowest on the kHz

560 spectrum and consist of the lowest average minimum and maximum frequencies, Type B's INS

561 frequencies extend the highest on the song type spectrum and present the highest minimum and

562 maximum average frequencies, and Type C's INS minimum and maximum frequency measures

563 are intermediate between the song types (Table 1). Although the three INS types have similar

564 frequency spans, their separation in minimum and maximum frequencies and large-scale

565 distributions may bear some resemblance to the large-scale geographic variations in frequency 
566

567

568

569

570

571

572

573

574

575

576

577

578

579

580

581

582

583

584

585

586

587

588

peaks and span of Chowchilla songs that resulted from isolation in Pleistocene refugia. Origins of the INS variations in Louisiana Waterthrush are obscure. The INS patterns of the three types are not restricted to localized occurrence and therefore results of this study do not readily support pattern variance specifically in the INS portion of the song having arisen on non-contiguous locally isolated streams. We were unable to detect any clinal patterns in the INS that might indicate a drift-like process had led to the three variations. The aforementioned merger of the glacial maximum with the Embayment would have provided a southeastern refugial isolation event in which a subpopulation's INS pattern could have potentially diverged, but it was not the only Pleistocene isolating scenario in that region. Another possibility might be derived from the numerous studies in recent years [41] that have highlighted the potential role of isolation in other glacial refugia as an explanation for current distributions of many organisms, including

Parulidae, and this explanation could apply to Louisiana Waterthrush if a subpopulation were to have undergone such an isolation period in a northerly refugium in what would have been theoretically favorable circumstances for INS variation to arise. Genetic research in the eastern United States within Louisiana Waterthrush's breeding range has established that northerly refugia were maintained in the northern Appalachians region and in the Midwest in areas that gave rise to variations in multiple taxa and harbored deciduous trees that could have potentially afforded suitable habitat. A Pleistocene refugium has been indicated for the sugar maple tree species Acer saccharum in the Northeast and a subsequent postglacial migration route from this refugium proposed from the periglacial areas of the Pennsylvania region [78] near a congregation of Type A and C singers. Another refugium in the Midwest, where Type B currently predominates, sustained an unglaciated keyhole of habitat in the Driftless Area where several species of mammals, deciduous plants, and amphibians survived [79—83]. The woody 
vine Smilax sp. survived the LGM in a northern refugium in that area, resulting in an isolated population in the Driftless Area separated from other populations east of the Embayment [77].

After evaluating the mapped distributions of the three identified Louisiana Waterthrush song types, we hypothesize that geographic relationships between INS variations and former Pleistocene glacial boundaries in separate parts of the breeding range could represent contemporary patterns in the type distributions that are indicative of separate evolutionary lineages in three subpopulations shaped either wholly or in part by glaciation-related isolation events. Although this hypothesis may offer a reasonable explanation for the differing distributions, support is inconclusive. We hope this initial exploration of the topic will spur further investigation into potential geographic congruency between the INS portion of the songs and former glacial limits, and also into whether the distributions of the SNS portion of the songs represent smaller-scale dialects.

\section{Acknowledgements}

This endeavor would not have been possible without open access to the large number of spectrograms available through the archives provided by The Cornell Laboratory of

Ornithology's eBird and Macaulay Library, and xeno-canto. We thank all of the recordists who unselfishly placed their hard-won spectrograms into the public domain. We also thank Philip Dixon and Tyler M. Harms at Iowa State University for statistical assistance, and we are grateful to reviewers who provided valuable guidance that significantly improved our approach in this manuscript. 

Lond, B, Biol Sci. 2002; 357:493-503. 
9. Thielcke G. On the origin of divergence of learned signals (songs) in isolated populations. Ibis 1973; 115:511-6. in repertoire size in an island population of an Australian songbird. Ibis 2003; tundra vole (Microtus oeconomus) in Beringia. Mol Ecol. 2004; 13:135-148. doi: 10.1046/j.1365-294X.2003.02026.x. 

structure: the effects of vicariant isolation, habitat type and body size. Anim Behav. 78. 
671

672

673

674

675

676

677

678

679

680

681

682

683

684

685

686

687

688

689

690

19. Kroodsma DE. Geographical variation and functions of song types in warblers (Parulidae). Auk 1981; 98:743-51.

20. Mundinger PC. Microgeographic and macrogeographic variation in the acquired vocalizations of birds. In: Acoustic communication in birds, Kroodsma DE, Miller EH, editors. New York: Academic Press; 1982. Vol 2, pp 147-208.

21. Milligan MM, Verner J. Inter-population song dialect discrimination in the White-crowned Sparrow. Condor 1971; 73:208-13.

22. Kroodsma DE. Two North American song populations of the Marsh Wren reach distributional limits in the central Great Plains. Condor 1989; 91:332-40.

23. Kroodsma DE. Two species of Marsh Wren (Cistothorus palustris) in Nebraska? Nebraska Bird Review 1988; 56:40-2.

24. Lanyon WE. The Comparative Biology of the Meadowlarks (Sturnella) in Wisconsin. Cambridge, Massachusetts: Publications of the Nuttall Ornithological Club, No. 1; 1957. 

breasted meadowlarks (Sturnella spp.) using mitochondrial and sex-linked markers. Auk 2008; 125:869-79.

695

26. Ordal JM. Effect of Sympatry on meadowlark vocalizations. Condor 1974; $78: 100-1$ a spatially explicit model testing the role of vocal learning. Anim Behav. 2003; 65:671-681. doi.org/10.1006/anbe.2003.2081. influence hummingbird speciation: genetic, acoustic and morphological divergence in the wedge-tailed sabrewing (Campylopterus curvipennis). BMC Evol Biol. 2011; 11: 38. doi:10.1186/1471-2148-11-38. songs of Golden-crowned Sparrows (Zonotrichia atricapilla). Auk 2016; 133:520-9. DOI: 10.1642/AUK-16-27.1 
30. Mattsson BJ, Master TL, Mulvihill RS, Robinson WD. Louisiana Waterthrush (Parkesia motacilla), version 1.0. In: Birds of the World, Poole AF editor). Ithaca, NY: Cornell Lab of Ornithology 2020. doi.org/10.2173/bow.louwat.01

31. Whitaker DM., Eaton SW. Northern Waterthrush (Parkesia noveboracensis), version 1.0. In: Birds of the World, Poole AF editor. Ithaca, NY: Cornell Lab of Ornithology 2020. doi.org/10.2173/bow.norwat.01.

32. Mattsson BJ. Louisiana Waterthrush ecology and conservation in the Georgia Piedmont. 2006. PhD thesis, University of Georgia, Athens, Georgia, U.S.A.

33. Machtans CS, Villard M-A, Hannon SJ. Use of riparian buffer strips as movement corridors by forest birds. Conserv Biol. 1996; 10:1366-79.

34. Eaton SW. A life history study of the Louisiana Waterthrush. Wilson Bull. 1958; 70:211-36.

35. Pieplow N. Peterson Field Guide to bird sounds of Eastern North America. Boston, MA and New York (NY): Houghton Mifflin Harcourt. 2017. 
36. Ruegg KC, Hijmans RJ, Moritz C. Climate change and the origin of migratory pathways in the Swainson's thrush, Catharus ustulatus. J Biogeogr 2006; 33:1172-82. epoch. Nat Commun. 2019; 10, 4342. doi.org/10.1038/s41467-019-12357-5.

38. Mengel RM. The probable history of species formation in some northern Wood Warblers (Parulidae). Living Bird 1964; 3:9-43.

39. Bermingham E, Rohwer S, Freeman S, Wood C. Vicariance biogeography in the Pleistocene and speciation in North American wood warblers: a test of Mengel's model. Proc Natl Acad Sci U S A. 1992; 15:89: 6624-28. doi: 10.1073/pnas.89.14.6624.

40. Cabanne GS, Calderon LP, Arias NT, Flores P, Pessoa R, d'Horta F et al. Effects of Pleistocene climate changes on species ranges and evolutionary processes in the Neotropical Atlantic Forest. Biol J Linn Soc Lond. 2016; 119:856-72. doi: 10.1111/bij.12844.

41. Hewitt GM. The genetic legacy of the Quaternary ice ages. Nature 2000; 405:907-13. 

In: Quaternary History of the United States, Gillespie AR, Porter S. editors. Nature 2005; 434:491-94. 
47. Reinertsen DL. Guide to the geology of the Galena area: Jo Daviess County, Illinois, Lafayette County, Wisconsin. Illinois State Geological Survey/Fieldtrip guidebook No. 1992D 1992.

48. Péwé TL. The periglacial environment of the United States in late Wisconsin time. In: Late Quaternary environments of the United States, Volume 1, The late Pleistocene. Wright HE Jr. editor. Minneapolis, MN: University of Minnesota Press, 1993. pp 157-89.

49. French HM, Millar SWS. Permafrost at the time of the Last Glacial Maximum (LGM) in North America. Boreas 2014; 43:667-77. doi:10.1111/bor.12036.

50. Vandenberghe J, French HM, Gorbunov A, Marchenko S, Velichko AA, Jin H, et al. Last Permafrost Maximum (LPM) map of the Northern Hemisphere: permafrost extent and mean annual air temperatures, 25-17 ka BP. Boreas 2014; 43:652-66. 10.1111/bor.12070. ISSN 0300-9483.

51. Miller CE Jr. The Late Pleistocene-Early Holocene in Central Pennsylvania. Map p. 4 in Pennsylvania Geology 2019; 49 (2):3-13. http://docs.dcnr.pa.gov/cs/groups/public/documents/document/v49no2.pdf. 
52. Wiley EO, Mayden RL. Species and speciation in phylogenetic systematics, with examples from the North American fish fauna. Annals of the Missouri Botanical Garden 1985; 72:596-635.

53. Gill FB, Mostrom AM, Mack AL. Speciation in North American chickadees: I. Patterns of mtDNA genetic divergence. Evolution 1993; 47:195-212.

54. Inoue K, Monroe EM, Elderkin CL, Berg, DJ. Phylogeographic and population genetic analyses reveal Pleistocene isolation followed by high gene flow in a wideranging but endangered freshwater mussel. Heredity 2014; 112:282-90.

55. Thesing BD, Noyes RD, Starkey DE, Shepard DB. Pleistocene climatic fluctuations explain the disjunct distribution and complex phylogeographic structure of the Southern Red-backed Salamander, Plethodon serratus. Evol Ecol. 2015; 30:89-104. doi 10.1007/s10682-015-9794-3.

56. Cushing EM, Boswell EH, Hosman RL. General Geology of the Mississippi Embayment. USGS Professional Paper 448-B 1964. 28 p.

57. Van Arsdale RB, Cox RT. The Mississippi's Curious Origins. Scientific American January 2007. 

fishes: A test of the Pleistocene vicariance hypothesis. Evolution 1997; 51:885-97.

59. Highton R, Webster TP. Geographic protein variation and divergence in populations of the salamander Plethodon cinereus. Evolution 1976; 30:33-45. contact of two highly divergent mitochondrial lineages in spotted salamanders (Ambystoma maculatum). Evolution 2003; 57: 1631-52. evides (Percidae: Etheostomatinae): an additional test of the Central Highlands pre-Pleistocene vicariance hypothesis. Molecular Ecology 2001; 10:2235-40. Waterthrush. J Field Ornithol. 1998; 69:288-298. Thesis, Univ. of Connecticut, Storrs, 1981. 
69. Fisher RA. The use of multiple measurements in taxonomic problems. Annals of Eugenics 1936; 7:179-188.

64. Smith WJ, Smith AM. Information about behaviour provided by Louisiana Waterthrush, Seiurus motacilla (Parulinae), songs. Anim Behav. 1996; 51:785-99.

65. Spector DA. Wood warbler song systems: a review of Paruline singing behaviors. Current Ornithol. 1992; 9:199-238.

66. Bolsinger JS. Use of two song categories by Golden-cheeked Warblers. Condor 2000; 102:539-52.

67. Macaulay Sound Library, Cornell Laboratory of Ornithology. http://macaulaylibrary.org.

68. xeno-canto. Sharing bird songs from around the world. http://www.xeno canto.org/species/Parkesia-motacilla. 
70. Ho TK. Random decision forests. Pages 278-282 in Proceedings of the 3rd International Conference on Document Analysis and Recognition, Montreal, QC, 1416 August 1995.

71. Sanders JE, Merguerian C. The glacial geology of New York City and vicinity, In: The Geology of Staten Island, New York, Field guide and proceedings, editor Benimoff AI. The Geological Association of New Jersey, XI Annual Meeting, 1994. 296 p.

72. Sevon WD. Fleegor GM, Shepps VC. Pennsylvania and the ice age. Harrisburg, PA: Pennsylvania Geological Survey Education Series 6, 1999.

73. Boulding JR. Pre-Illinoian Glacial Deposits in Indiana (2): Are Glacial Tills and Outwash West of the Knobstone Escarpment in Brown County Pre-Illinoian? BSW Working Paper 2, Version 1.0. 2018. doi 10.13140/RG.2.2.15429.96488.

74. Killey MM. Quaternary Glaciations in Illinois. Illinois State Geologic Survey, Geonote \#3 by D.J. Berggren, revised.

75. Gray HH, Letsinger SL. A history of glacial boundaries in Indiana: Indiana Geological Survey Special Report 71, 2011. 
76. Arthur JK, Taylor RE. Ground-Water Flow Analysis of the Mississippi Embayment Aquifer System, South-Central United States. USGS Professional Paper 1416-I, 1998.

77. Li P, Li M, Shi Y, Zhao Y, Wan Y, Fu, C, et al. Phylogeography of North American herbaceous Smilax (Smilacaceae): combined AFLP and cpDNA data support a northern refugium in the Driftless Area. Am J Bot. 100:801-14. genetic variation and differentiation in sugar maple from tropical Central America to temperate North America. BMC Evol Biol. 15:1-14. North American conifer. Mol Ecol. 2004; 13:2735-47. and white-footed mice in relation to the individualistic nature of species. Mol Ecol. 2006; 15:4003-20. 

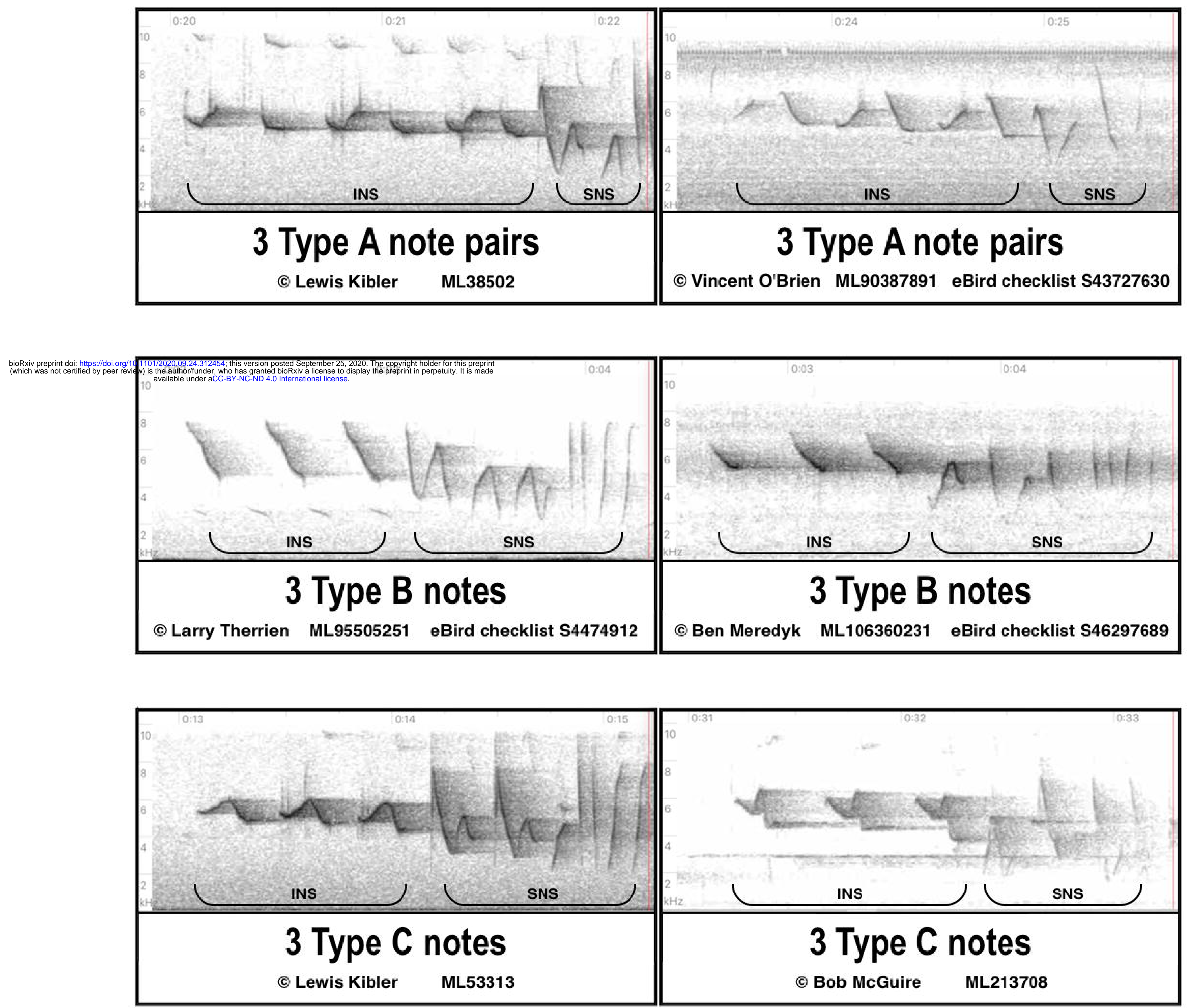


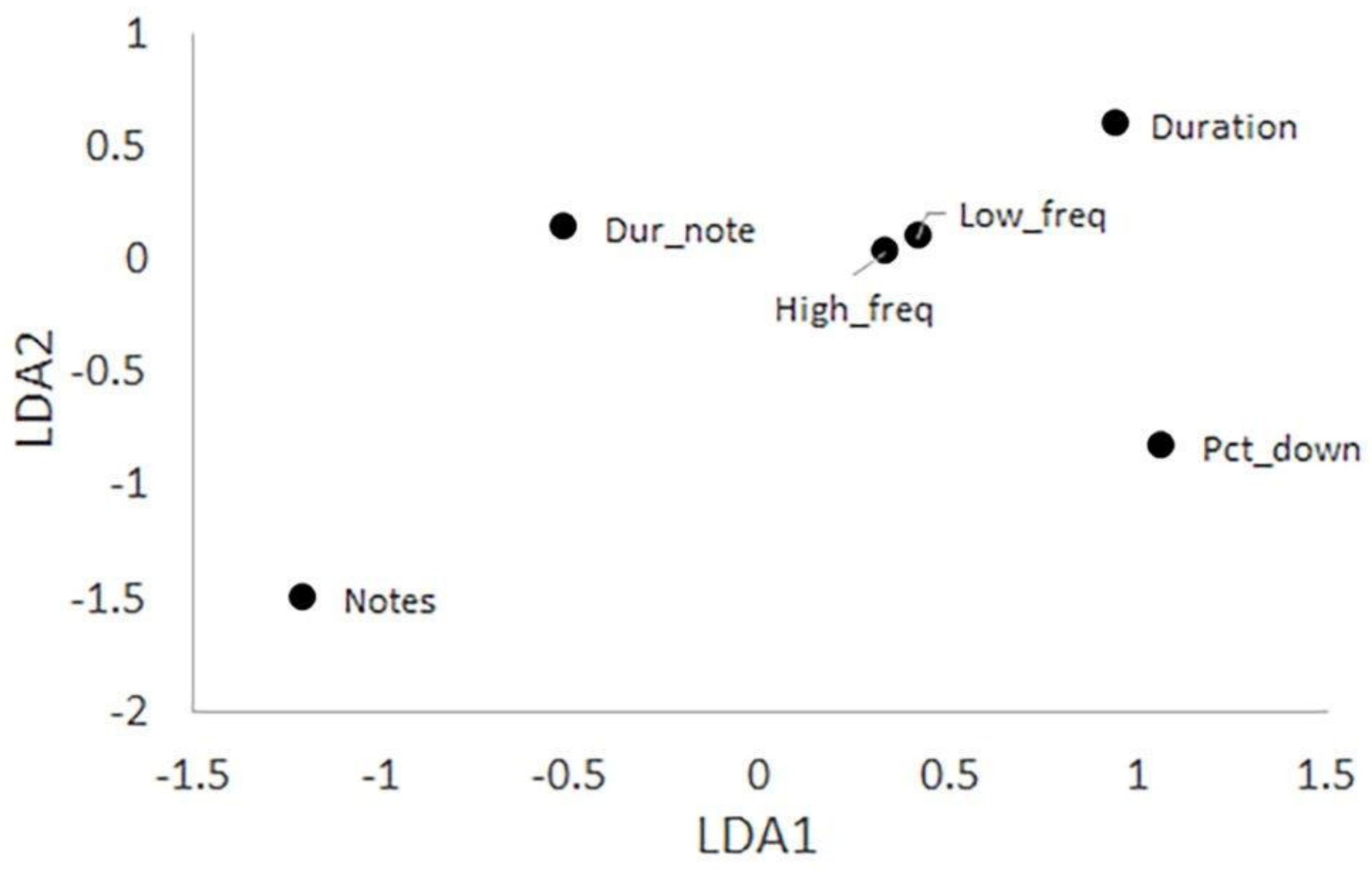




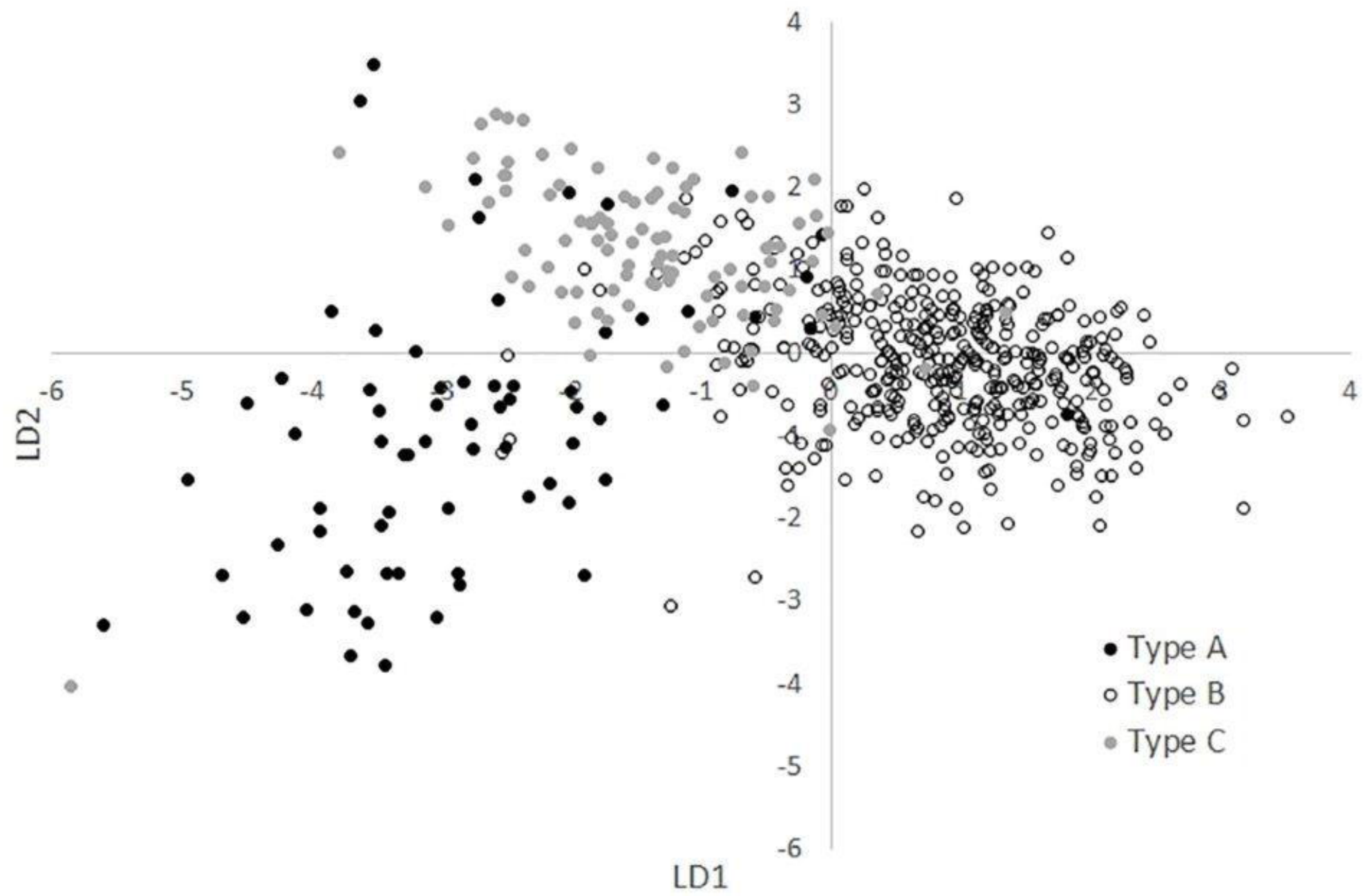




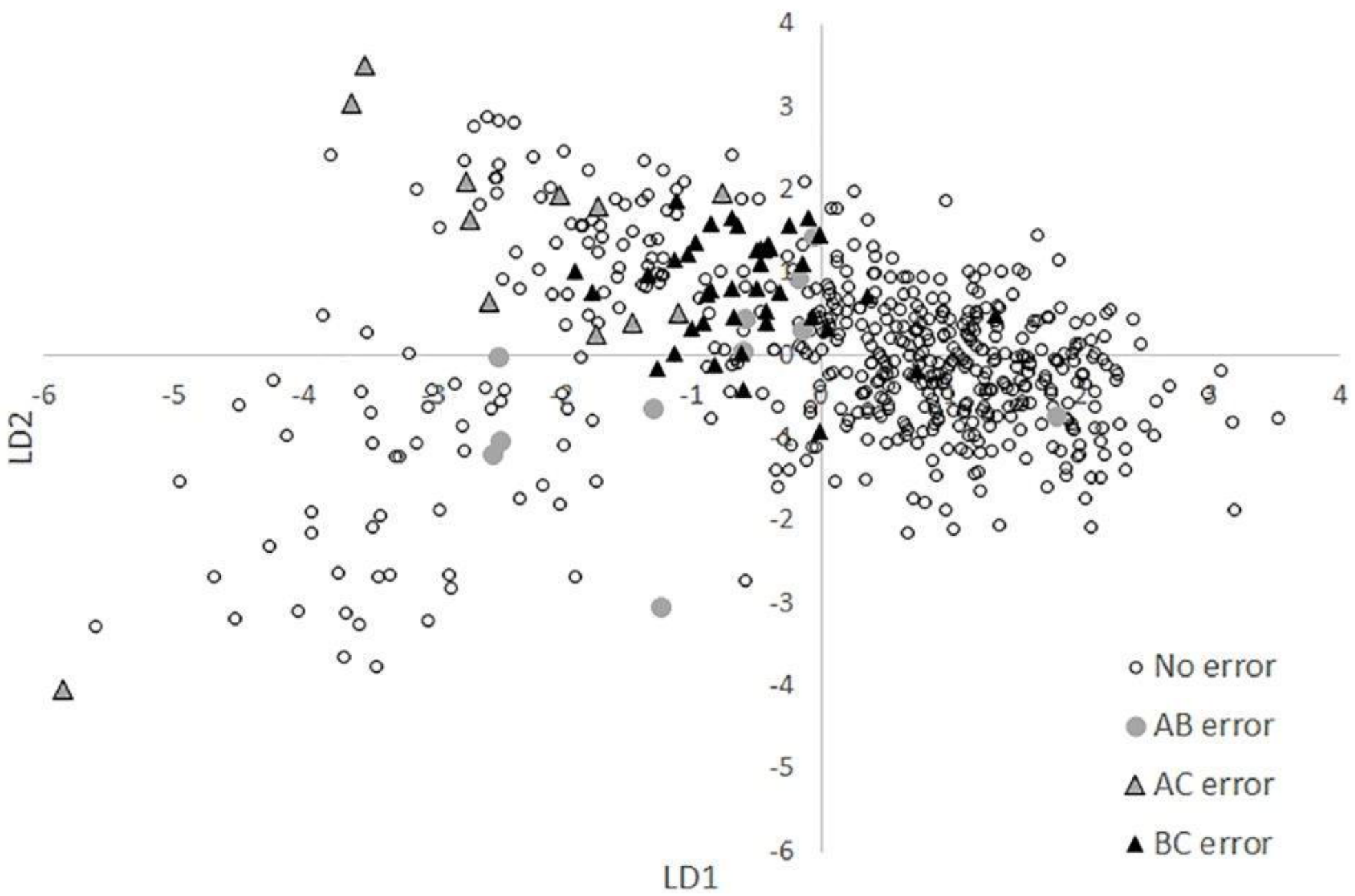




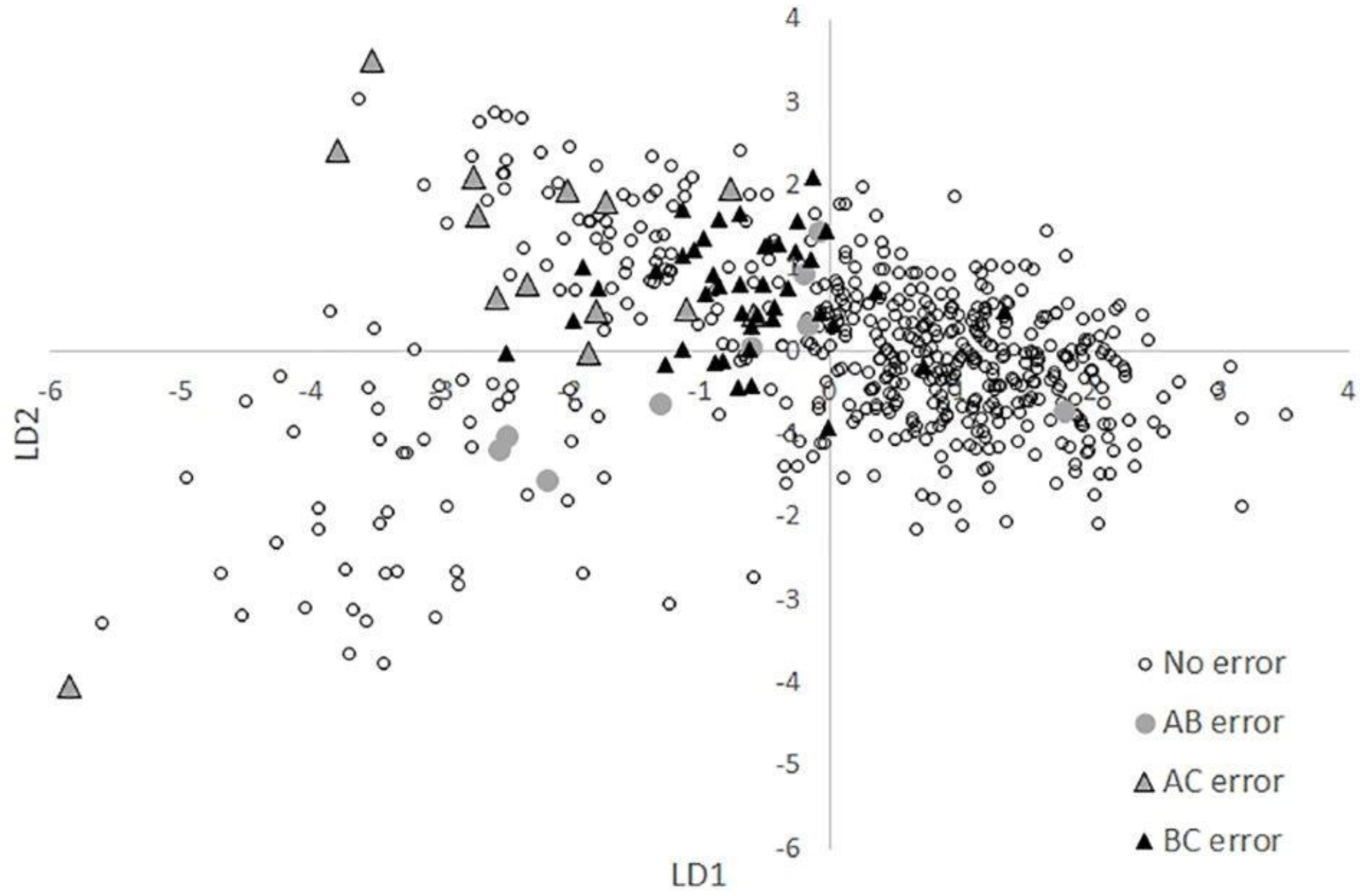



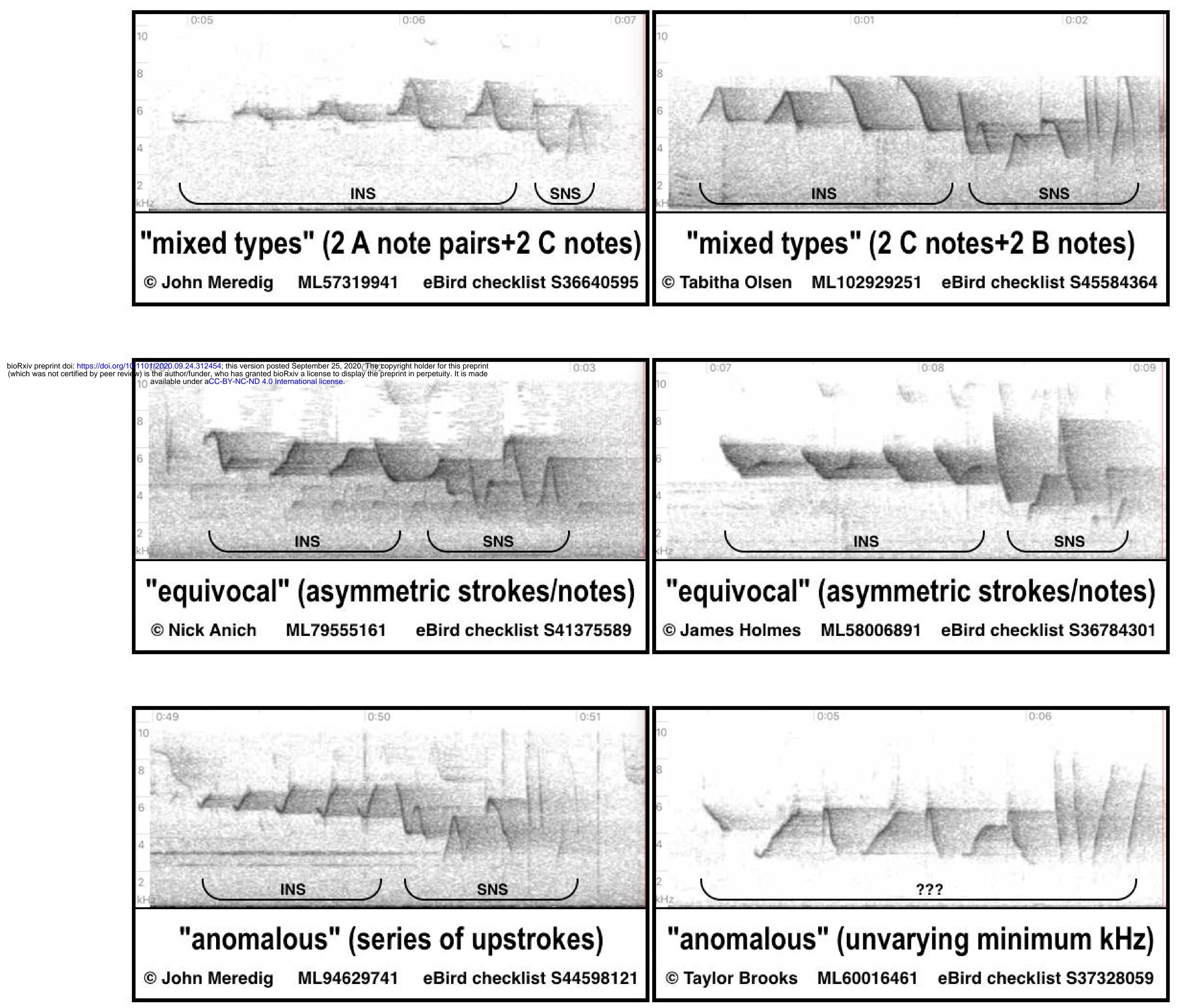


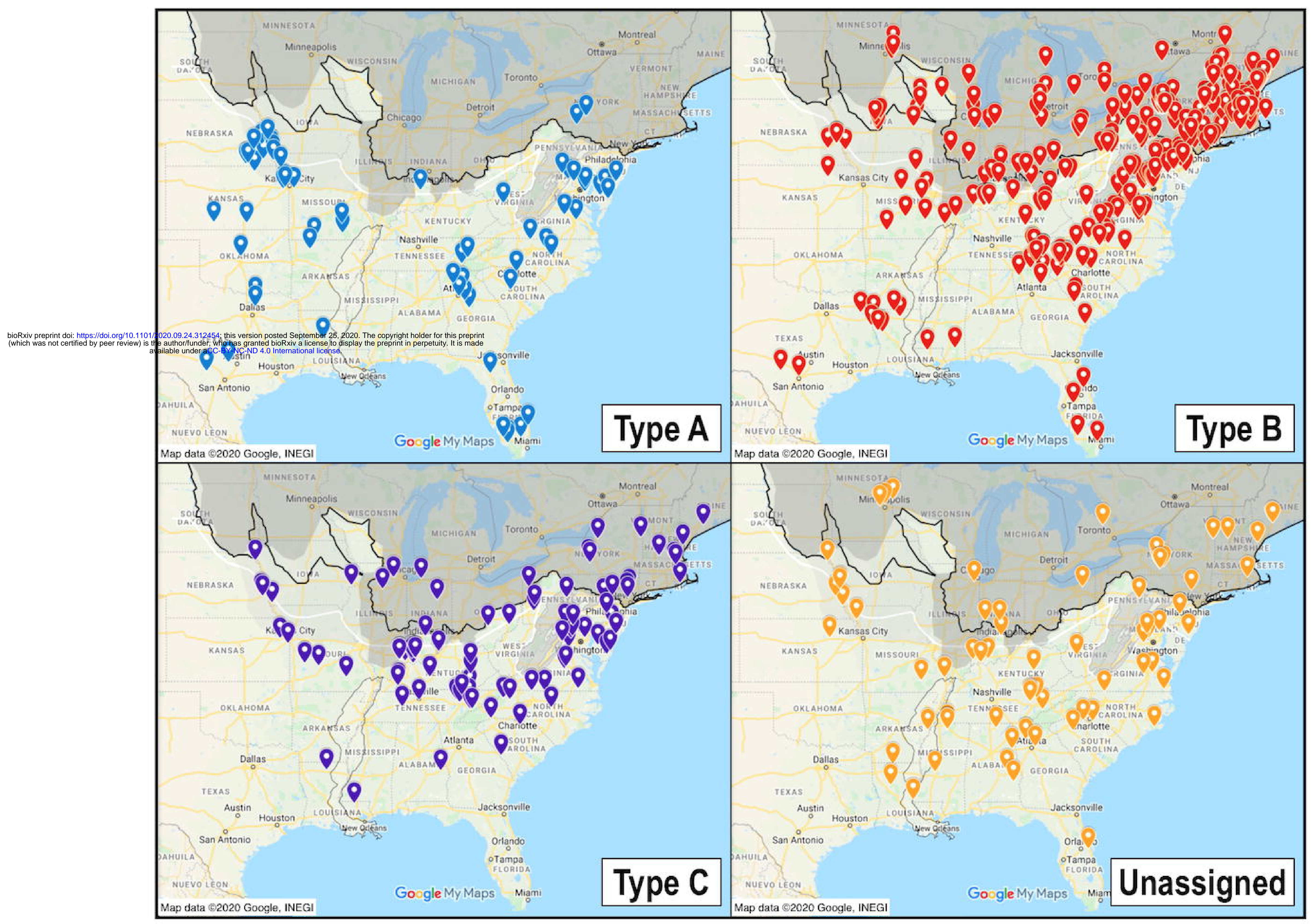

